\title{
Using archaeology for population estimates and land-use reconstructions: a perspective from Central Europe
}

Jan Kolár ${ }^{1,2}$, M. Macek ${ }^{3,4}$ and P. Szabó

\section{Estimation of past population dynamics on a regional scale over thousands of years is a difficult research task. We} offer insights based on spatio-temporal modeling and discuss the significance of the archaeological evidence for population and land-use reconstructions.

The size and density of populations are among the most significant factors influencing the character of human-environment interactions, and, in combination with information on subsistence strategies, enable researchers to create a better picture of past land use. However, quantifying or estimating population size and density for the distant past is a challenging task.

Continental-to-global-scale land-use reconstructions based on archaeological data are important because historical land use affected land cover which, in turn influenced global and regional climate (e.g. de Noblet-Ducoudré et al. 2012; Pongratz et al. 2010; see Editorial, this issue). However, the importance of largescale archaeological data for paleoscience became widely recognized only recently (e.g. Ellis 2015; Gaillard et al. 2015)

\section{Character of archaeological evidence} and population estimates

Archaeology differs from many paleosciences with respect to the nature of the data it can provide. Archaeologists usually focus on a few sites or specialize in one period, a few specific types of artifacts or methods of analysis. Thus, producing a chronologically long and continuous perspective on population or settlement dynamics presents an unusually complex task.

Several approaches have been used to produce population estimates based on information from archaeological data. One can work with absolute or relative assessments of past populations (Müller 2013). Absolute population estimates usually provide densities (persons per $\mathrm{km}^{2}$ ) and are related to environmental factors, such as carrying capacity, and ethnographical or archaeological data. Relative population estimates rely on the assumption that the amount of archaeological evidence directly reflects population size and density, although the values are not translated into absolute values. The prevalent technique to produce relative population estimates is the use of summed radiocarbon probability distributions, which are based on radiocarbon dates of bones, wood or seeds from archaeological contexts (e.g. Bevan et al. 2017; Shennan et al. 2013; Timpson et al. 2014). Although the method is criticized for a diverse range of biases (e.g. financial situation of countries and national research funding agencies allowing for more analyses, research traditions and interests, past mobility and subsistence strategies; see Torfing 2015), it seems capable of providing valuable insights into the long-term history of human activities over large regions. The most important advantage of this approach is that it overcomes the common archaeological focus on specific sites or periods and produces quantified spatio-temporal models easily comparable with paleoenvironmental proxies that may cover thousands of years and large areas (Bevan et al. 2017).

\section{Human activities and land use} in the Holocene

The Czech Republic currently does not have sufficient numbers of radiocarbon

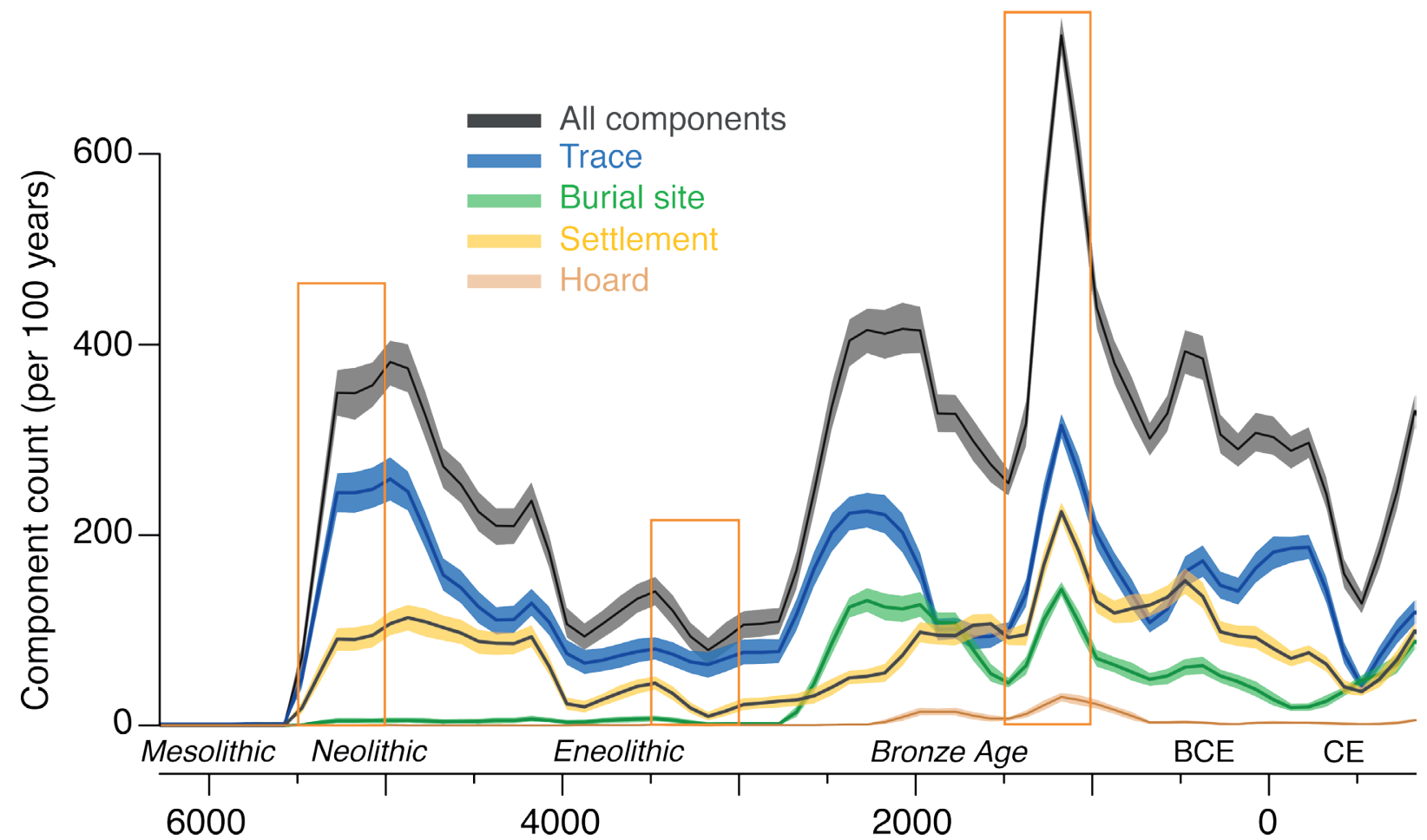

Figure 1: Human-activity model for Moravia $\left(26,804 \mathrm{~km}^{2}\right.$; Czech Republic) based on Monte Carlo simulations, classified according to the origin of activity. 
dates to use these as the primary estimators of past population, but databases of archaeological sites and excavations are available for the entire area (Kolář et al. 2016a; Kuna et al. 2015). The data in these databases cover most of human history and can be used to model past human activities in both space and time.

Understanding the drivers behind and effects of past population dynamics is of high importance. This can be done only by producing archaeological results which are easily comparable with climatic or paleoecological proxies. Our region of interest is Moravia (the eastern part of Czech Republic), from which we collected data on all available archaeological sites and finds dated between 10,000 BCE and $1250 \mathrm{CE}$.

We analyzed archaeological evidence from 1685 modern civil parishes (basic administrative units), which contain records on 18,736 archaeological components characterized according to basic function (settlement, burial site, hillfort, traces, etc.).

Spatial precision differs for all components (precisely located components vs. finds located only to the parish); we thus used the parish as the common spatial denominator. Temporal precision of the archaeological dating also varies. Some components have imprecise dates ("Neolithic-Eneolithic": 5400 BC-2000 BC for most non-diagnostic polished stone artifacts) while others have been dated to the nearest decade.

Adopting the relative approach to understand population dynamics in time, we used several modeling procedures (for details, see Kolář et al. 2016b). Monte Carlo simulations helped us to quantify the uncertainty in the temporal density of components. One thousand potential time series were simulated, where every archaeological component was assigned to a random single year from within its time span. We created a cumulative plot of these simulation runs for each dated component (Fig. 1). In Figure 1, the thickness of the data category envelopes indicates the temporal uncertainty for each category.

We see a rapid increase of archaeological evidence at the beginning of the Neolithic, which was connected with a change in lifestyle and the adoption of agriculture and animal herding. The subsequent period shows a decrease in evidence, which ends during the transition to the Bronze Age. This long-term quantified model of human activities can be readily compared to paleoecological and climatic models, as we showed in Kolár et al. (in press).

The spatial modeling of past human activities is based on parish occupancy likelihood, which is calculated as the proportion of simulation runs in which a parish was considered occupied (for details see Kolár et al. 2016b). These values were later interpolated with the natural neighbor method in a geographic information system (GIS). Land use comprising cereal cultivation and animal herding covered a much larger

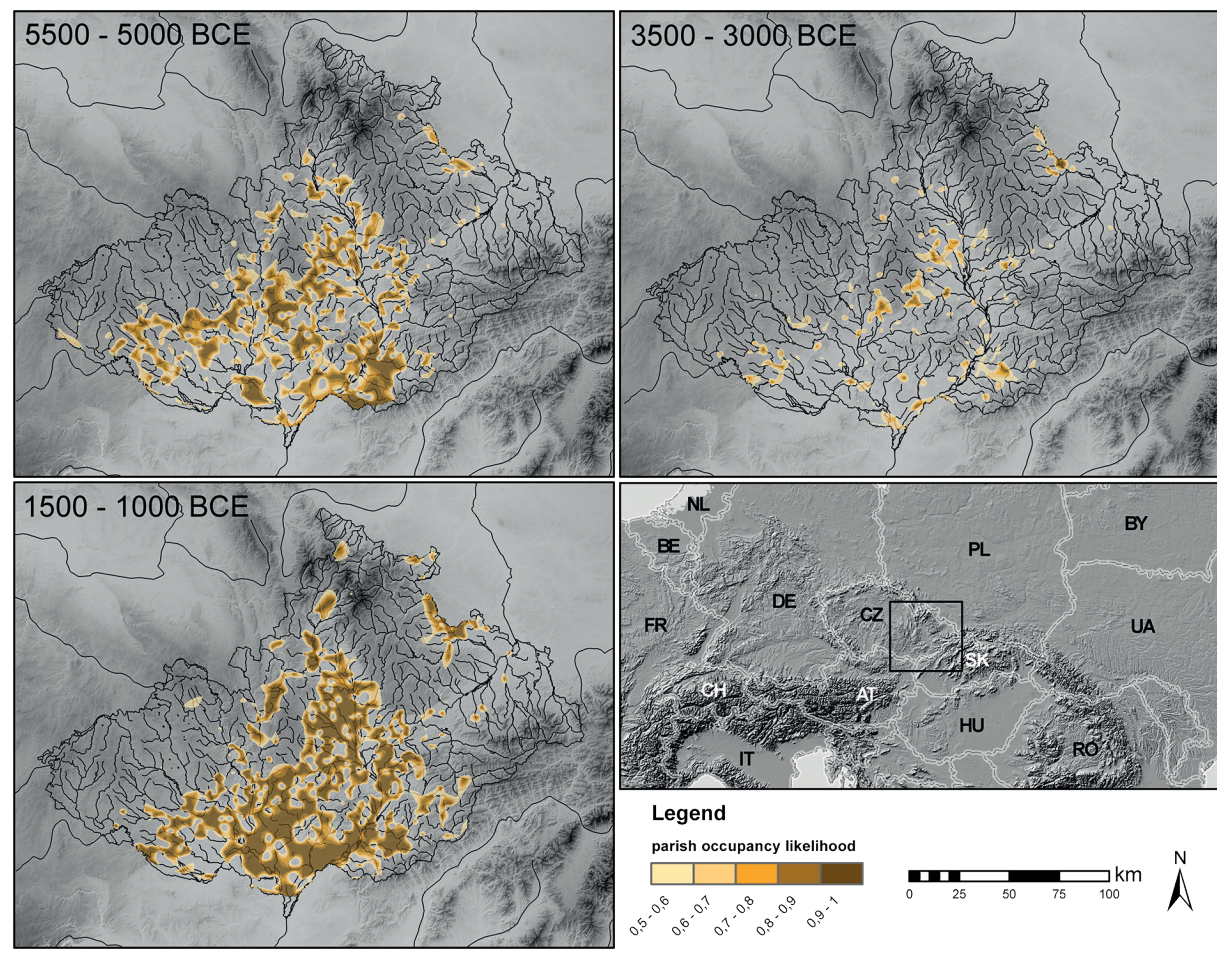

Figure 2: Spatial patterns of human activities in Moravia in specific time blocks of Neolithic (5500-5000 BCE), Eneolithic (3500-3000 BCE) and Later Bronze Age (1500-1000 BCE).

extent at the beginning of the Neolithic, around $5500 \mathrm{BCE}$, than centuries later during the Central European Eneolithic (35003000 BCE; Fig. 2). Later in the Bronze Age, especially after $1500 \mathrm{BCE}$, human activities became much more intense, and human communities settled in most of the available lowlands.

\section{What can archaeology offer?}

Population estimates and land-use reconstructions based on archaeological data at a global level depend on the existence of specialized databases of radiocarbon dates or sites. The quality of available datasets varies regionally. The observed dynamics in archaeologically detected human activities most probably reflect population dynamics in general, but possible sources of bias must be acknowledged and addressed. The most significant qualitative and quantitative transformations of anthropogenic remains are caused by pre- and post-depositional taphonomic processes. The way people built their dwellings or buried their dead, the scale of erosion, and intensity of surveys and excavations all have an impact on available datasets. As such, we need to exercise caution in our use of these reconstructions. However, these diverse existing datasets and regional models, including knowledge about past existing social organization and farming technologies, can be incorporated into the assessment of past land use and population dynamics on a global level, enabling the study of relationships between environmental changes and social aspects of past populations.

\section{ACKNOWLEDGEMENTS}

This work was supported as a long-term research development project no. RVO 67985939 and by a grant of the Fulbright Commission.

\section{AFFILIATIONS}

Department of Vegetation Ecology, Institute of Botany of the Czech Academy of Sciences, Brno, Czech Republic

${ }^{2}$ Institute of Archaeology and Museology, Masaryk University, Brno, Czech Republic

${ }^{3}$ Department of GIS and Remote Sensing, Institute of Botany of the Czech Academy of Sciences, Průhonice, Czech Republic

${ }^{4}$ Department of Botany, Charles University, Prague, Czech Republic

\section{CONTACT}

Jan Koláŕ: jan.kolar@ibot.cas.cz

\section{REFERENCES}

Bevan A et al. (2017) PNAS 114: E10524-E10531

de Noblet-Ducoudré N et al. (2012) J Climate 25: 3261-3281

Gaillard M-J, Land Cover6k Interim Steering Group members (2015) PAGES Mag 23: 38-39

Kolář J et al. (2016a) Archaol Korresp 46: 539-554 Koláŕ J et al. (2016b) Archaeometry 58: 513-528

Koláŕ J et al. (in press) Archaeol Anthrop Sci

Kuna M et al. (2015) In: Kuna M et al. (Eds) Structuring Archaeological Evidence. The Archaeological Map of the Czech Republic and Related Information Systems. Institute of Archaeology of the Czech Academy of Sciences, 25-67

Müller J (2013) In: Kadrow S and Włodarczak P (Eds) Environment and Subsistence - Forty Years after Janusz Kruk's "Settlement Studies...,". Dr. Rudolf Habelt GmbH, 1-14

Pongratz J et al. (2010) Geophys Res Lett 37: L08702

Shennan S et al. (2013) Nat Commun 4: 2486 Timpson A et al. (2014) J Archaeol Sci 52: 549-557 Torfing T (2015) J Archaeol Sci 63: 193-198 